\title{
Suboptimal Image Reason
}

National Cancer Institute

\section{Source}

National Cancer Institute. Suboptimal Image Reason. NCI Thesaurus. Code C86975.

An image of inferior quality, may still be adequate to make a diagnosis. 